University of Nebraska - Lincoln

DigitalCommons@University of Nebraska - Lincoln

Prevalence and genotypes of Enterocytozoon bieneusi in weaned beef calves on cow-calf operations in the USA

\author{
Mónica Santín \\ USDA-ARS, monica.santin-duran@ars.usda.gov \\ David Dargatz \\ USDA \\ Ronald Fayer \\ USDA-ARS, ronald.fayer@ars.usda.gov
}

Follow this and additional works at: https://digitalcommons.unl.edu/usdaarsfacpub

Santín, Mónica; Dargatz, David; and Fayer, Ronald, "Prevalence and genotypes of Enterocytozoon bieneusi in weaned beef calves on cow-calf operations in the USA" (2012). Publications from USDA-ARS / UNL Faculty. 1279.

https://digitalcommons.unl.edu/usdaarsfacpub/1279

This Article is brought to you for free and open access by the U.S. Department of Agriculture: Agricultural Research Service, Lincoln, Nebraska at DigitalCommons@University of Nebraska - Lincoln. It has been accepted for inclusion in Publications from USDA-ARS / UNL Faculty by an authorized administrator of DigitalCommons@University of Nebraska - Lincoln. 


\title{
Prevalence and genotypes of Enterocytozoon bieneusi in weaned beef calves on cow-calf operations in the USA
}

\author{
Mónica Santín • David Dargatz • Ronald Fayer
}

This article is a U.S. government work, and is not subject to copyright in the United States.

Received: 30 September 2011 /Accepted: 21 November 2011 /Published online: 7 December 2011

(C) Springer-Verlag (outside the USA) 2011

\begin{abstract}
To determine the prevalence and genotype distribution of Enterocytozoon bieneusi in weaned beef calves in the USA, fecal samples were collected from 819 calves (618 months of age) from 49 operations. Feces were sieved and subjected to density gradient centrifugation to remove fecal debris and to concentrate spores. DNA extracted from each sample was subjected to the polymerase chain reaction (PCR) to amplify the complete internal transcriber spacer (ITS). All PCR-positive specimens were sequenced to determine the genotype(s) present. Overall, E. bieneusi was detected in $34.8 \%$ of the 819 fecal samples. The highest prevalence was found in the Midwest region (42.7\%) followed by the South $(35.8 \%)$ and the West (23.2\%). The prevalence of E. bieneusi varied considerably from operation to operation $(0-100 \%)$. A prevalence of $100 \%$ was observed in three operations, one in the Midwest and two in the South; E. bieneusi was not found in six operations, three in the South and three in the West. Sequence analysis revealed the presence of six genotypes, four previously reported (I, J, BEB4, and type IV) and two
\end{abstract}

Mention of trade names or commercial products in this publication is solely for the purpose of providing specific information and does not imply recommendation or endorsement by the US Department of Agriculture (USDA). USDA is an equal opportunity provider and employer.

M. Santín $(\bowtie) \cdot$ R. Fayer

United States Department of Agriculture, Environmental

Microbial and Food Safety Laboratory, Animal and Natural

Resources Institute Agricultural Research Service,

Building 173, BARC-East, 10300 Baltimore Avenue,

Beltsville, MD 20705, USA

e-mail: monica.santin-duran@ars.usda.gov

\section{Dargatz}

United States Department of Agriculture, Animal and Plant Health Inspection Service, Centers for Epidemiology and Animal Health, Fort Collins, CO 80526, USA novel genotypes (BEB8 and BEB9). Mixed infections were identified in five specimens, three contained I and BEB4 and two contained J and BEB4. Most of the positive calves (238 of $285)$ harbored genotypes with zoonotic potential including I (59), J (108), BEB4 (65), type IV (1), mixed I/BEB4 (3), and mixed J/BEB4 (2).

Microsporidia have been recognized as opportunistic pathogens of immunocompromised patients, but immunocompetent individuals have also been found to be infected (Didier 2005; Sak et al. 2011a). Enterocytozoon bieneusi is the species found most frequently in humans, mainly associated with chronic diarrhea and wasting syndrome (van Gool et al. 1995; Sobottka et al. 1998). E. bieneusi has also been found in a variety of wild, farm, and companion mammals and in birds (Santín and Fayer 2009a, 2011). It has been reported in surface water suggesting the possibility that domestic and wild animals could be sources (Dowd et al. 1998).

Over 100 genotypes of $E$. bieneusi have been identified based on nucleotide sequence polymorphisms in the 243-bp internal transcriber spacer (ITS) region of the rRNA gene. Some genotypes appear host specific for humans, others specific for animals, and still others appear zoonotic (Santín and Fayer 2011). Twenty-three genotypes have been found in feces from both humans and animals (Table 1). Of those, nine were found in cattle and humans (Table 1). Cattle are considered to be the only hosts for nine other genotypes (BEB3, PtEb XI, BEB7, 4948 FL-2, CEbA, CEbD, CEbF, $\mathrm{M}$, and $\mathrm{N}$ ) and for BEB6, also identified from goats (Dengjel et al. 2001; Fayer et al. 2007; Feng et al. 2011; Lee 2007, 2008; Lobo et al. 2006b; Santín et al. 2005; Sulaiman et al. 2004). E. bieneusi in cattle was first reported in three calves in Germany (Rinder et al. 2000) and shortly thereafter in seven additional calves (Dengjel et al. 2001). Extensive studies of 


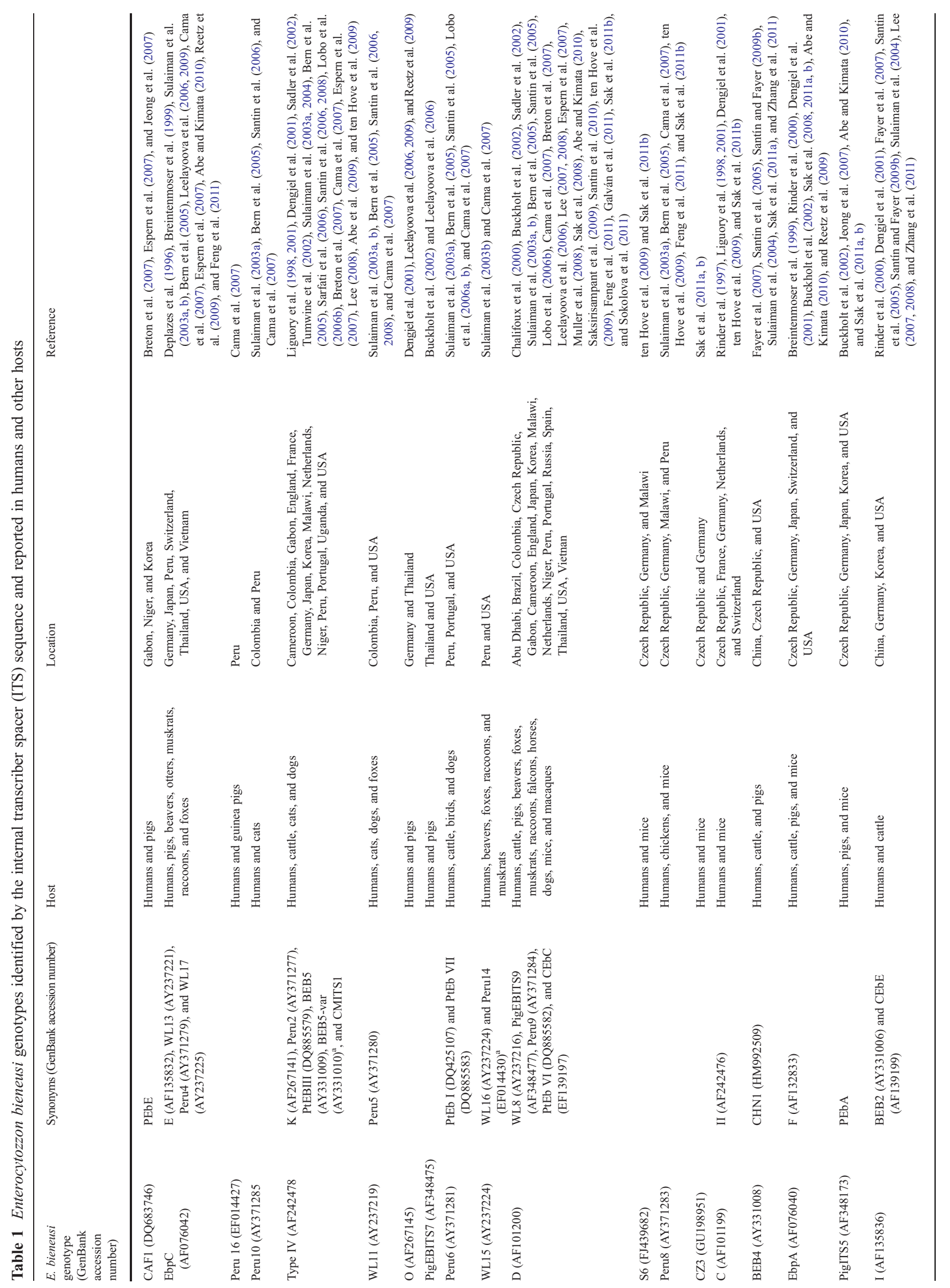


dairy cattle, from neonates to mature milking cows, in farms along the east coast of the USA have reported infection with several genotypes of E. bieneusi (Fayer et al. 2003, 2007; Santín et al. 2004, 2005). A longitudinal study of 30 dairy cattle from birth to 24 months of age on a farm in eastern USA found that $100 \%$ of the animals became infected with $E$. bieneusi at some time during the study (Santín and Fayer 2009b). Genotypes I, J, and BEB4 were identified, with genotype I being the dominant genotype, infecting all calves and present in each calf for the longest duration (Santín and Fayer 2009b). Although E. bieneusi was detected in dairy and beef cattle in Korea, data did not distinguish dairy and beef breeds (Lee 2007).

The absence of data on the prevalence $E$. bieneusi in beef cattle led to the present study which was conducted to determine the occurrence of $E$. bieneusi in beef cattle using fecal specimens obtained from cow-calf operations throughout the USA and to determine which genotypes were present.

\section{Materials and methods}

Cow-calf operation location and sample collection

The US Department of Agriculture (USDA) National Animal Health Monitoring System conducted the Beef 20072008 study on cow-calf operations in 24 states (USDA 2008). Fecal samples for E. bieneusi testing were available from operations in 20 of the 24 states from three regions (Midwest-Iowa, Kansas, Missouri, Nebraska, North Dakota, and South Dakota; South-Alabama, Georgia, Louisiana, Mississippi, Oklahoma, Tennessee, Texas, and Virginia; and West - California, Colorado, Idaho, New Mexico, Oregon, and Wyoming). Participating producers each collected up to 20 fecal samples directly from the rectum of 6- to 18-month-old weaned calves or from fresh fecal pats on the ground from calves to assess parasite burden.

Sample processing, PCR, gene sequencing, and phylogenetic analysis

Specimens received at the Environmental Microbial and Food Safety Laboratory were examined for the presence of E. bieneusi after spores were concentrated from feces by sieving and $\mathrm{CsCl}$ density gradient centrifugation to remove fecal debris and concentrate spores as described (Fayer et al. 2007). Each $15 \mathrm{~g}$ sample of feces was suspended in $35-\mathrm{ml}$ $\mathrm{dH}_{2} \mathrm{O}$ and passed through a sieve with a $45-\mu \mathrm{m}$ pore size. The filtered suspension was transferred to a $50-\mathrm{ml}$ conical tube, the volume adjusted to $50 \mathrm{ml}$ with $\mathrm{dH}_{2} \mathrm{O}$, and the tube was centrifuged at $1,800 \times \mathrm{g}$ for $15 \mathrm{~min}$. The pellet was resuspended in $25 \mathrm{ml} \mathrm{dH_{2 }} \mathrm{O} ; 25 \mathrm{ml} \mathrm{CsCl}$ (1.4 specific gravity) 
was added, and the contents mixed by vortexing. The tube was centrifuged at $300 \times \mathrm{g}$ for $20 \mathrm{~min}$, and $4 \mathrm{ml}$ of supernatant was aspirated from the surface. The aspirate was washed twice with $\mathrm{dH}_{2} \mathrm{O}$, and the final pellet was suspended in $500 \mu \mathrm{l}$ of $\mathrm{dH}_{2} \mathrm{O}$ for subsequent DNA processing.

DNA was extracted from each specimen using a DNeasy Tissue Kit (Qiagen, Valencia, California). The slightly modified protocol, described below, employed reagents from the manufacturer. Fifty microliters of processed specimen was suspended in $180 \mu \mathrm{l}$ of ATL buffer, thoroughly mixed, $20 \mu \mathrm{l}$ of proteinase $\mathrm{K}(20 \mathrm{mg} / \mathrm{ml})$ was added, and the suspension was mixed again. Following overnight incubation at $55^{\circ} \mathrm{C}$, $200 \mu \mathrm{l}$ of $\mathrm{AL}$ buffer was added. The remaining protocol followed manufacturer's instructions except, to recover more DNA, the nucleic acid was eluted in $100 \mu$ l of AE buffer.

The polymerase chain reaction (PCR) amplification was performed using a set of nested primers specific for E. bieneusi that amplified the ITS and portions of the flanking large and small subunits of the rDNA ( $\sim 400 \mathrm{bp}$ ). The outer primers were EBITS3 (5' GGTCATAGGGATGAAGAG 3') and EBITS4 (5' TTCGAGTTCTTTCGCGCTC $3^{\prime}$ ), and the inner primers were EBITS1 (5' GCTCTGAATATCTATGGCT 3') and EBITS2.4 (5' ATCGCCGACGGATCCAAGTG 3') (Buckholt et al. 2002). The reaction mixture $(50 \mu \mathrm{L})$ contained $1.5 \mathrm{mM} \mathrm{MgCl}_{2}, 50 \mathrm{mM} \mathrm{KCl}, 20 \mathrm{mM}$ Tris- $\mathrm{HCl}$ $(\mathrm{pH}=9), 0.2 \mathrm{mM}$ dNTPs, $50 \mathrm{pmol}$ of each primer, $2.5 \mathrm{U}$ of Taq (Qbiogene Inc., Carlsbad, California), and $2.5 \mu \mathrm{L}$ of BSA $(0.1 \mathrm{~g} / 10 \mathrm{~mL})$. After denaturation at $94^{\circ} \mathrm{C}$ for $3 \mathrm{~min}$, the first PCR samples were subjected to 35 cycles of amplification (denaturation at $94^{\circ} \mathrm{C}$ for $30 \mathrm{~s}$, annealing at $57^{\circ} \mathrm{C}$ for $30 \mathrm{~s}$, and elongation at $72^{\circ} \mathrm{C}$ for $40 \mathrm{~s}$ ), followed by a final extension at $72^{\circ} \mathrm{C}$ for $10 \mathrm{~min}$. Conditions for the secondary PCR were identical to the primary PCR except only 30 cycles were carried out with an annealing temperature of $55^{\circ} \mathrm{C}$. These reactions produced fragments of 435 and $390 \mathrm{bp}$, respectively. Negative and positive controls were included in all sets of PCRs, as well as amplifying the negative control from the first PCR in the second reaction to check for low level contamination. The PCR products were subjected to electrophoresis in a $1 \%$ agarose gel and visualized by staining the gel with ethidium bromide.

All PCR-positive samples were directly sequenced with the inner set of primers used for the secondary PCR. PCR products were purified using EXO-SAP enzyme (USB Corporation, Cleveland, Ohio). Purified products were sequenced at $10 \mu \mathrm{L}$ reactions using Big Dye ${ }^{\mathrm{TM}}$ chemistries, and an ABI3130 sequence analyzer (Applied Biosystems, Foster City, California). Sequence chromatograms from each strand were aligned and inspected using Lasergene software (DNASTAR, Inc., Madison, Wisconsin). The sequences were compared with sequences in the GenBank database by BLAST analysis. Nucleotide sequences obtained in the present study were deposited in the GenBank database under accession numbers JQ044398 and JQ044399.
Phylogenetic analyses

Sequences from all E. bieneusi genotypes identified in cattle and humans were aligned using the ClustalW algorithm using the MEGA version 4 (Tamura et al. 2007). ClustalW determines that when a gap is inserted it can be removed only by editing, so final alignment adjustments were made manually to remove artificial gaps. Phylogenetic and molecular evolutionary analyses were made using MEGA 4 (Tamura et al. 2007). Phylogenetic inference was by the neighbor-joining method of Saitou and Nei (1987). Genetic distance was calculated with the Kimura two-parameter model.

\section{Results}

Feces from 819 calves from 49 cow-calf operations were examined for E. bieneusi by PCR (Table 2). At least one positive calf was found in $43(87.8 \%)$ of the cow-calf operations. Overall, 285 of 819 calves (34.8\%) were found infected. The highest prevalence was found in the Midwest region $(42.7 \%)$ followed by the South $(35.8 \%)$ and the West (23.2\%). The prevalence of E. bieneusi varied considerably from operation to operation ( $0-100 \%)$. A prevalence of $100 \%$ was observed in three operations, one in the Midwest region and two in the South; E. bieneusi was not identified in six operations, three in the South and three in the West.

All 285 PCR positive specimens were sequenced to determine the genotype(s) and sequences were compared with those in the GenBank database by BLAST analysis. In Table 2, genotypes of $E$. bieneusi identified in each cow-calf operation are presented. The sequence analysis revealed the presence of six different genotypes (Table 2). Four of those genotypes, I, J, BEB4, and type IV, were previously described in cattle. Two new genotypes, BEB8 and BEB9, were identified for the first time in this study. Of the 285 positive specimens, the most prevalent genotype was $\mathrm{J}$ (in 108 specimens), followed by BEB4 (in 65 specimens), I (in 59 specimens), and BEB8 (in 41 specimens). Genotypes BEB9 and type IV were identified in only six and one specimen, respectively. Mixed infections were identified in five specimens, three with I and BEB4 and two with J and BEB4.

A phylogenetic analysis was carried out on all E. bieneusi genotypes identified in humans and cattle and available in GenBank (Fig. 1). The two new genotypes identified in this study, BEB8 and BEB9, were placed in the cluster with genotypes that are most commonly isolated from cattle.

\section{Discussion}

E. bieneusi genotypes I, J, BEB4, BEB8, BEB9, and type IV were detected by PCR in 285 (34.8\%) of 819 weaned beef 
Table 2 Numbers of calf samples examined and genotypes of Enterocytozoon bieneusi found by region

\begin{tabular}{|c|c|c|c|c|c|}
\hline Region & Number of operations & $\begin{array}{l}\text { Number of samples } \\
\text { per operation }\end{array}$ & $\begin{array}{l}\text { Number of positives } \\
\text { per operation }\end{array}$ & Prevalence & E. bieneusi genotypes identified \\
\hline \multirow[t]{20}{*}{ Midwest } & 20 & 20 & 9 & 45 & BEB4 (9) \\
\hline & & 20 & 12 & 60 & $\mathrm{~J}(9), \mathrm{I}(1)$, and BEB4 (2) \\
\hline & & 20 & 13 & 65 & $\mathrm{~J}(3), \mathrm{I}(6)$, and BEB4 (4) \\
\hline & & 20 & 8 & 40 & $\mathrm{~J}(5), \mathrm{I}(2)$, and BEB4 (1) \\
\hline & & 20 & 5 & 25 & $\mathrm{~J}(4)$ and BEB8 (1) \\
\hline & & 20 & 5 & 25 & $\mathrm{~J}(4)$ and BEB8 (1) \\
\hline & & 20 & 5 & 25 & $\mathrm{~J}(3)$ and BEB8 (2) \\
\hline & & 20 & 1 & 5 & $\mathrm{~J}(1)$ \\
\hline & & 20 & 15 & 75 & I (9), BEBE4 (5), and BEBE4-like (1) \\
\hline & & 19 & 6 & 31.6 & $\mathrm{~J}(2)$ and I (4) \\
\hline & & 18 & 4 & 22.2 & BEB4 (4) \\
\hline & & 17 & 8 & 47.1 & $\mathrm{~J}(6)$ and BEB4 (2) \\
\hline & & 17 & 8 & 47.1 & $\mathrm{~J}(3), \mathrm{I}(1), \mathrm{BEB} 4$ (4), and \\
\hline & & 16 & 1 & 6.3 & BEB4 (1) \\
\hline & & 16 & 5 & 31.3 & $\mathrm{~J}(5)$ \\
\hline & & 15 & 11 & 73.3 & BEB4 (1) and BEB8 (10) \\
\hline & & 12 & 11 & 91.7 & I (11) \\
\hline & & 11 & 8 & 72.7 & BEB8 (8) \\
\hline & & 8 & 8 & 100 & BEB4 (1) and BEB8 (7) \\
\hline & & 8 & 1 & 12.5 & BEB4 (1) \\
\hline \multirow[t]{15}{*}{ South } & 15 & 20 & 9 & 45 & I (2) and BEB4 (7) \\
\hline & & 20 & 7 & 35 & I (1), BEB4 (3), BEB9 (1), and mixed I/BEBE4 (2) \\
\hline & & 20 & 0 & 0 & \\
\hline & & 20 & 6 & 30 & BEB4 (6) \\
\hline & & 20 & 6 & 30 & I (6) \\
\hline & & 20 & 14 & 70 & $\mathrm{~J}(14)$ \\
\hline & & 20 & 5 & 25 & $\mathrm{~J}(5)$ \\
\hline & & 19 & 6 & 31.6 & $\mathrm{~J}(5)$ and BEB4 (1) \\
\hline & & 18 & 12 & 66.7 & I (1), J (6), and BEB4 (5) \\
\hline & & 17 & 5 & 29.4 & $\mathrm{~J}(1)$ and BEB4 (4) \\
\hline & & 14 & 2 & 14.3 & BEB4 (2) \\
\hline & & 10 & 0 & 0 & \\
\hline & & 8 & 8 & 100 & $\mathrm{~J}(3)$ and I (5) \\
\hline & & 3 & 3 & 100 & $\mathrm{~J}(3)$ \\
\hline & & 3 & 0 & 0 & \\
\hline \multirow[t]{14}{*}{ West } & 14 & 20 & 2 & 10 & I (2) \\
\hline & & 20 & 0 & 0 & \\
\hline & & 20 & 4 & 20 & $\mathrm{~J}(3)$ and BEB4 (1) \\
\hline & & 20 & 1 & 5 & Mixed BEB4/J (1) \\
\hline & & 20 & 3 & 15 & $\mathrm{~J}(1)$ and I (2) \\
\hline & & 20 & 7 & 35 & I (3) and BEB9 (4) \\
\hline & & 20 & 5 & 25 & $\mathrm{~J}(5)$ \\
\hline & & 20 & 16 & 80 & $\begin{array}{l}\mathrm{J}(8), \mathrm{I}(1), \mathrm{BEB} 4 \text { (4), type IV (1), J/BEB4 (1), } \\
\text { and I/BEB4 (1) }\end{array}$ \\
\hline & & 20 & 3 & 15 & I (1) and BEB4 (2) \\
\hline & & 20 & 13 & 65 & J (9), I (1), and BEB4 (3) \\
\hline & & 17 & 3 & 17.6 & BEB4 (3) \\
\hline & & 17 & 1 & 5.9 & BEB4 (1) \\
\hline & & 9 & 0 & 0 & \\
\hline & & 7 & 0 & 0 & \\
\hline Total & 49 & 819 & 285 & 34.8 & $\begin{array}{l}\text { J (108), I (59), BEB4 (65), BEB8 (41), BEB9 (6), } \\
\text { type IV (1), mixed I/BEB4 (3), and mixed J/BEB4 (2) }\end{array}$ \\
\hline
\end{tabular}


Fig. 1 Phylogenetic relationships among Enterocytozoon bieneusi genotypes identified in humans and other hosts, and cattle inferred by a neighbor-joining analysis of the ITS rRNA gene sequence, based on genetic distances calculated by the Kimura two-parameter model. Nucleotide sequences determined in this study are identified with a filled triangle before the genotype name. Genotypes identified in humans (filled circle); genotypes identified in humans, cattle, and other hosts (filled square); genotypes identified in humans and other hosts that do not include cattle (empty circles); genotypes identified in cattle (empty squares). Bootstrap values of less than $75 \%$ are not shown

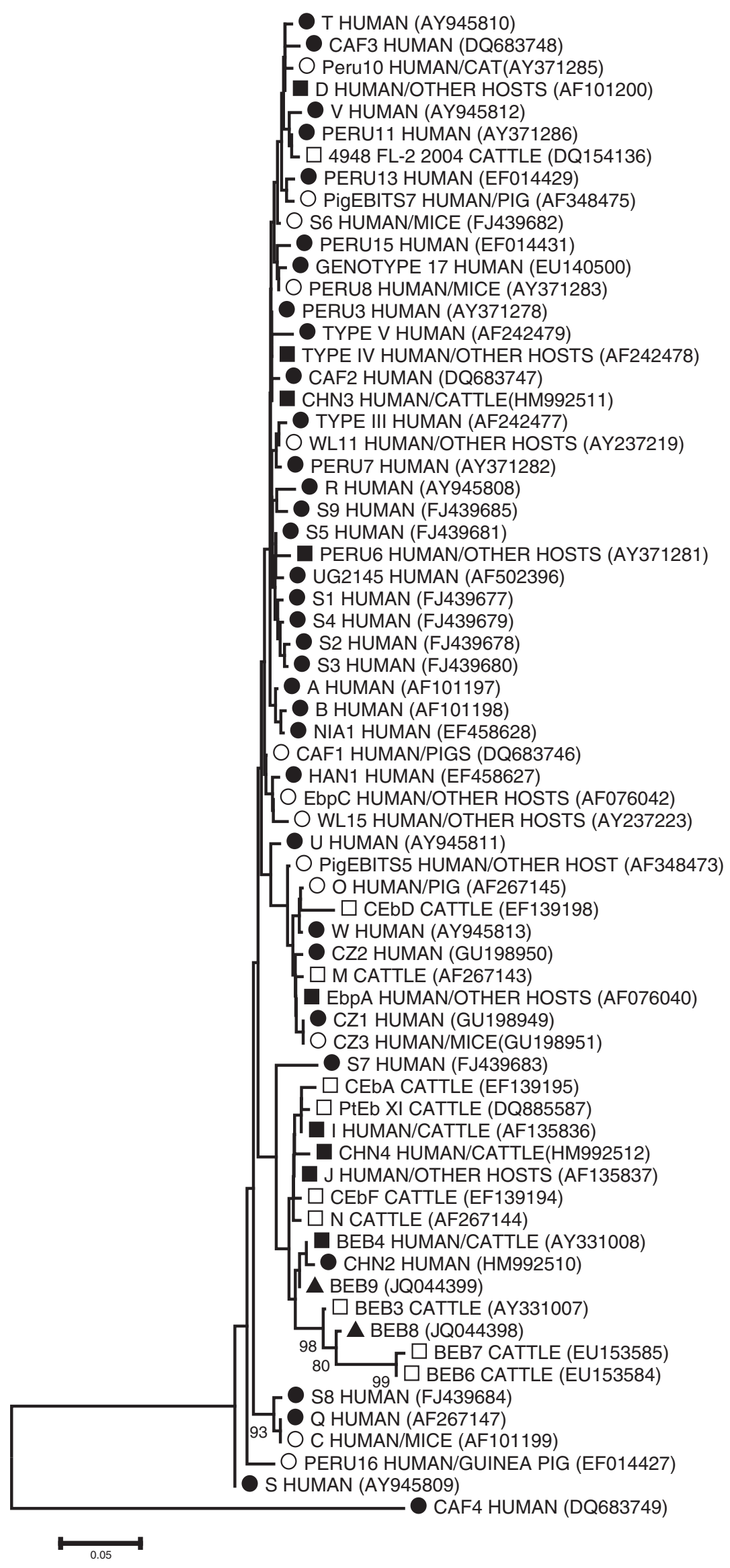


calves (6-18 months of age) in the present study. This is the first report of $E$. bieneusi genotypes and their prevalence in beef cattle. The first report of $E$. bieneusi in cattle was from three calves in a herd of 28 cattle with diarrhea in Germany (Rinder et al. 2000). The first report of E. bieneusi in cattle in North America found 13 positive dairy calves from six farms in five states out of 413 calves examined on 15 farms in seven eastern states (Fayer et al. 2003). It appeared from further studies at many of the same farms that the prevalence of $E$. bieneusi infection in dairy cattle increased as cattle increased in age. Of 452 post-weaned, 3- to 8-month-old calves, $13 \%$ were found positive for E. bieneusi (Santín et al. 2004). Of 571 heifers, 12 - to 24 months of age, $23 \%$ were positive for E. bieneusi (Santín et al. 2005). The prevalence of $E$. bieneusi infection then appeared to decrease in mature dairy cattle. Of 541 milking cows, $4.4 \%$ were positive for $E$. bieneusi (Fayer et al. 2007). Of 30 dairy calves followed up from birth to 24 months of age, the same age-related trend in prevalence of infection was observed and eventually all were detected as positive at one point or another with $E$. bieneusi (Santín and Fayer 2009b).

In Korea, of 538 fecal samples from cattle, approximately $15 \%$ were positive; summer rates were the highest (Lee 2007). The prevalence related to dairy or beef cattle was not reported.

Based on the sequence data from the ITS region, of the six genotypes of $E$. bieneusi identified among the 285 PCR positive fecal genotypes I, J, BEB4, and BEB8 were the most prevalent. Except for newly identified BEB8, these results are in agreement with data from dairy cattle in which these genotypes were also the most common (Fayer et al. 2007; Santín and Fayer 2009b; Sulaiman et al. 2004). Genotypes I, J, and BEB4 were thought to be cattle specific, but recently, the host range of these genotypes has increased, having been identified in humans in China and the Czech Republic (Sak et al. 2011a; Zhang et al. 2011). Genotype J has also been identified in chickens in Germany (Reetz et al. 2002).

E. bieneusi has been identified in water sources as well as in wild, domestic, and food-producing farm animals, raising concerns of water-borne, food-borne, and zoonotic transmission. The identification of the three most common genotypes of E. bieneusi of cattle (I, J, and BEB4), now found in humans, changes the paradigm from genotypes thought to be cattle-specific to genotypes with zoonotic (bidirectional) potential. It has been suggested that although $E$. bieneusi has broad host specificity, transmission is more restricted, with some genotypes able to circulate within a given host species but only occasionally being transmitted to another host (Henriques-Gil et al. 2010). This appears to fit the pattern for genotypes I, J, and BEB4. Genotype type IV in contrast, was identified not only in one calf in the present study and in a few other cattle from Korea, Portugal, and the USA (Lee 2008; Sulaiman et al. 2004) but also in cats from
Germany, Colombia, Japan, and Portugal (Abe et al. 2009; Dengjel et al. 2001; Lobo et al. 2006b; Santín et al. 2006); in dogs from Colombia (Santín et al. 2008); and in humans from Gabon, Cameroon, Peru, England, Uganda, Niger, France, Malawi, and Netherlands (Bern et al. 2005; Breton et al. 2007; Cama et al. 2007; Espern et al. 2007; Liguory et al. 1998, 2001; Sadler et al. 2002; Sarfati et al. 2006; Sulaiman et al. 2003a; ten Hove et al. 2009; Tumwine et al. 2002).

We report that $34.8 \%$ of apparently healthy calves were infected with $E$. bieneusi. The identification of genotypes that also have been found in humans highlights the possible role of beef cattle as a source of environmental contamination with genotypes with zoonotic potential.

Acknowledgments The authors thank Meghan Heffron and Julie Headly for technical assistance.

\section{References}

Abe N, Kimata I (2010) Molecular survey of Enterocytozoon bieneusi in a Japanese porcine population. Vector Borne Zoonotic Dis 10:425-427

Abe N, Kimata I, Iseki M (2009) Molecular evidence of Enterocytozoon bieneusi in Japan. J Vet Med Sci 71:217-219

Bern C, Kawai V, Vargas D, Rabke-Verani J, Williamson J, ChavezValdez R, Xiao L, Sulaiman I, Vivar A, Ticona E, Navincopa M, Cama V, Moura H, Secor WE, Visvesvara G, Gilman RH (2005) The epidemiology of intestinal microsporidiosis in patients with HIV/AIDS in Lima, Peru. J Infect Dis 191:1658-1664

Breitenmoser AC, Mathis A, Bürgi E, Weber R, Deplazes P (1999) High prevalence of Enterocytozoon bieneusi in swine with four genotypes that differ from those identified in humans. Parasitology $118: 447-453$

Breton J, Bart-Delabesse E, Biligui S, Carbone A, Seiller X, OkomeNkoumou M, Nzamba C, Kombila M, Accoceberry I, Thellier M (2007) New highly divergent rRNA sequence among biodiverse genotypes of Enterocytozoon bieneusi strains isolated from humans in Gabon and Cameroon. J Clin Microbiol 45:2580-2589

Buckholt MA, Lee JH, Tzipori S (2002) Prevalence of Enterocytozoon bieneusi in swine: an 18-month survey at a slaughterhouse in Massachusetts. Appl Environ Microbiol 68:2595-2599

Cama VA, Pearson J, Cabrera L, Pacheco L, Gilman R, Meyer S, Ortega Y, Xiao L (2007) Transmission of Enterocytozoon bieneusi between a child and guinea pigs. J Clin Microbiol 45:2708-2710

Chalifoux LV, Carville A, Pauley D, Thompson B, Lackner AA, Mansfield KG (2000) Enterocytozoon bieneusi as a cause of proliferative serositis in simian immunodeficiency virus-infected immunodeficient macaques (Macaca mulatta). Arch Pathol Lab Med 124:1480-1484

Dengjel B, Zahler M, Hermanns W, Heinritzi K, Spillmann T, Thomschke A, Löscher T, Gothe R, Rinder H (2001) Zoonotic potential of Enterocytozoon bieneusi. J Clin Microbiol 39:44954499

Deplazes P, Mathis A, Muller C, Weber R (1996) Molecular epidemiology of Encephalitozoon cuniculi and firsts detection of Entercytozoon bieneusi in faecal samples from pigs. J Euk Microbiol 43:93S

Didier ES (2005) Microsporidiosis: an emerging and opportunistic infection in humans and animals. Acta Trop 94:61-76 
Dowd SE, Gerba CP, Pepper IL (1998) Confirmation of the humanpathogenic microsporidia Enterocytozoon bieneusi, Encephalitozoon intestinalis, and Vittaforma corneae in water. Appl Environ Microbiol 64:3332-3335

Espern A, Morio F, Miegeville M, Illa H, Abdoulaye M, Meyssonnier V, Adehossi E, Lejeune A, Cam PD, Besse B, Gay-Andrieu F (2007) Molecular study of Microsporidiosis due to Enterocytozoon bieneusi and Encephalitozoon intestinalis among human immunodeficiency virus-infected patients from two geographical areas: Niamey, Niger, and Hanoi, Vietnam. J Clin Microbiol 45:2999-3002

Fayer R, Santín M, Trout JM (2003) First detection of microsporidia in dairy calves in North America. Parasitol Res 90:383-386

Fayer R, Santín M, Trout JM (2007) Enterocytozoon bieneusi in mature dairy cattle on farms in the eastern United States. Parasitol Res 102:15-20

Feng Y, Li N, Dearen T, Lobo ML, Matos O, Cama V, Xiao L (2011) Development of a multilocus sequence typing tool for highresolution genotyping of Enterocytozoon bieneusi. Appl Environ Microbiol 77:4822-4828

Galván AL, Sánchez AM, Valentín MA, Henriques-Gil N, Izquierdo F, Fenoy S, del Aguila C (2011) First cases of microsporidiosis in transplant recipients in Spain and review of the literature. J Clin Microbiol 49:1301-1306

Henriques-Gil N, Haro M, Izquierdo F, Fenoy S, del Aguila C (2010) Phylogenetic approach to the variability of the microsporidian Enterocytozoon bieneusi and its implications for inter- and intrahost transmission. Appl Environ Microbiol 76:3333-3342

Jeong DK, Won GY, Park BK, Hur J, You JY, Kang SJ, Oh IG, Lee YS, Stein BD, Lee JH (2007) Occurrence and genotypic characteristics of Enterocytozoon bieneusi in pigs with diarrhea. Parasitol Res 102:123-128

Lee JH (2007) Prevalence and molecular characteristics of Enterocytozoon bieneusi in cattle in Korea. Parasitol Res 101:391-396

Lee JH (2008) Molecular detection of Enterocytozoon bieneusi and identification of a potentially human-pathogenic genotype in milk. Appl Environ Microbiol 74:1664-1666

Leelayoova S, Subrungruang I, Suputtamongkol Y, Worapong J, Petmitr PC, Mungthin M (2006) Identification of genotypes of Enterocytozoon bieneusi from stool samples from human immunodeficiency virus-infected patients in Thailand. J Clin Microbiol 44:3001-3004

Leelayoova S, Piyaraj P, Subrungruang I, Pagornrat W, Naaglor T, Phumklan S, Taamasri P, Suwanasri J, Mungthin M (2009) Genotypic characterization of Enterocytozoon bieneusi in specimens from pigs and humans in a pig farm community in Central Thailand. J Clin Microbiol 47:1572-1574

Liguory O, Davis F, Sarfati C, Derouin F, Molina JM (1998) Determination of types of Enterocytozoon bieneusi strains isolated from patients with intestinal microsporidiosis. J Clin Microbiol 36:1882-1885

Liguory O, Sarfati C, Derouin F, Molina JM (2001) Evidence of different Enterocytozoon bieneusi genotypes in patients with and without human immunodeficiency virus infection. J Clin Microbiol 39:2672-2674

Lobo ML, Xiao L, Cama V, Magalhaes N, Antunes F, Matos O (2006a) Identification of potentially human-pathogenic Enterocytozoon bieneusi genotypes in various birds. Appl Environ Microbiol 72:7380-7382

Lobo ML, Xiao L, Cama V, Stevens T, Antunes F, Matos O (2006b) Genotypes of Enterocytozoon bieneusi in mammals in Portugal. J Euk Microbiol 53:S61-S64

Müller MG, Kinne J, Schuster RK, Walochnik J (2008) Outbreak of microsporidiosis caused by Enterocytozoon bieneusi in falcons. Vet Parasitol 152:67-78

Reetz J, Rinder H, Thomschke A, Manke H, Schwebs M, Bruderek A (2002) First detection of the microsporidium Enterocytozoon bieneusi in non-mammalian hosts (chickens). Int $\mathrm{J}$ Parasitol 32:785-787

Reetz J, Nöckler K, Reckinger S, Vargas MM, Weiske W, Broglia A (2009) Identification of Encephalitozoon cuniculi genotype III and two novel genotypes of Enterocytozoon bieneusi in swine. Parasitol Int 58:285-292

Rinder H, Katzwinkel-Wladarsch S, Loscher T (1997) Evidence for the existence of genetically distinct strains of Enterocytozoon bieneusi. Parasitol Res 83:670-672

Rinder H, Dengjel B, Gothe R, Loscher T (2000) Microsporidosis of man: where is the reservoir? Mitt Osterr Ges Trop Med Parasitol 22:1-6

Sadler F, Peake N, Borrow R, Rowl PL, Wilkins EG, Curry A (2002) Genotyping of Enterocytozoon bieneusi in AIDS patients from the north west of England. J Infect 44:39-42

Saitou N, Nei M (1987) The neighbor-joining method: a new method for reconstructing phylogenetic trees. Mol Biol Evol 4:406-425

Sak B, Kvác M, Hanzlíková D, Cama V (2008) First report of Enterocytozoon bieneusi infection on a pig farm in the Czech Republic. Vet Parasitol 153:220-224

Sak B, Brady D, Pelikánová M, Květoňová D, Rost M, Kostka M, Tolarová V, Hůzová Z, Kváč M (2011a) Unapparent microsporidial infection among immunocompetent humans in the Czech Republic. J Clin Microbiol 49:1064-1070

Sak B, Kváč M, Květoňová D, Albrecht T, Piálek J (2011b) The first report on natural Enterocytozoon bieneusi and Encephalitozoon spp. infections in wild East-European House Mice (Mus musculus musculus) and West-European house mice (M. m. domesticus) in a hybrid zone across the Czech Republic-Germany border. Vet Parasitol 178:246-250

Saksirisampant W, Prownebon J, Saksirisampant P, Mungthin M, Siripatanapipong S, Leelayoova S (2009) Intestinal parasitic infections: prevalences in HIV/AIDS patients in a Thai AIDS-care centre. Ann Trop Med Parasitol 103:573-581

Santín M, Fayer R (2009a) Enterocytozoon bieneusi genotype nomenclature based on the internal transcribed spacer sequence: a consensus. J Euk Microbiol 56:34-38

Santín M, Fayer R (2009b) A longitudinal study of Enterocytozoon bieneusi in dairy cattle. Parasitol Res 105:141-144

Santín M, Fayer R (2011) Microsporidiosis: Enterocytozoon bieneusi in domesticated and wild animals. Res Vet Sci 90:363-3671

Santín M, Trout JM, Fayer R (2004) Prevalence of Enterocytozoon bieneusi in post-weaned dairy calves in the eastern United States. Parasitol Res 93:287-289

Santín M, Trout JM, Fayer R (2005) Enterocytozoon bieneusi genotypes in dairy cattle in the eastern United States. Parasitol Res 97:535-538

Santín M, Trout JM, Vecino JA, Dubey JP, Fayer R (2006) Cryptosporidium, Giardia and Enterocytozoon bieneusi in cats from Bogota (Colombia) and genotyping of isolates. Vet Parasitol 141:334-339

Santín M, Cortés Vecino JA, Fayer R (2008) Enterocytozoon bieneusi genotypes in dogs in Bogota, Colombia. Am J Trop Med Hyg 79:215-217

Santín M, Cortés Vecino JA, Fayer R (2010) A zoonotic genotype of Enterocytozoon bieneusi in horses. J Parasitolol 96:157-161

Sarfati C, Bourgeois A, Menotti J, Liegeois F, Moyou-Somo R, Delaporte E, Derouin F, Ngole EM, Molina JM (2006) Prevalence of intestinal parasites including microsporidia in human immunodeficiency virus-infected adults in Cameroon: a cross-sectional study. Am J Trop Med Hyg 74:162-164

Sobottka I, Schwartz DA, Schottelius J, Visvesvara GS, Pieniazek NJ, Schmetz C, Kock NP, Laufs R, Albrecht H (1998) Prevalence and clinical significance of intestinal microsporidiosis in human immunodeficiency virus-infected patients with and without diarrhea in Germany: a prospective coprodiagnostic study. Clin Infect Dis 26:475-480

Sokolova OI, Demyanov AV, Bowers LC, Didier ES, Yakovlev AV, Skarlato SO, Sokolova YY (2011) Emerging microsporidian 
infections in Russian HIV-infected patients. J Clin Microbiol 49:2102-2108

Sulaiman IM, Bern C, Gilman R, Cama V, Kawai V, Vargas D, Ticona E, Vivar A, Xiao L (2003a) A molecular biologic study of Enterocytozoon bieneusi in HIV-infected patients in Lima, Peru. J Euk Microbiol 50:591-596

Sulaiman IM, Fayer R, Lal AA, Trout JM, Schaefer FW, Xiao L (2003b) Molecular characterization of microsporidia indicates that wild mammals harbor host-adapted Enterocytozoon spp. as well as human-pathogenic Enterocytozoon bieneusi. Appl Environ Microbiol 69:4495-4501

Sulaiman IM, Fayer R, Yang C, Santín M, Matos O, Xiao L (2004) Molecular characterization of Enterocytozoon bieneusi in cattle indicates that only some isolates have zoonotic potential. Parasitol Res 92:328-334

Tamura K, Dudley J, Nei M, Kumar S (2007) MEGA4: Molecular Evolutionary Genetics Analysis (MEGA) software version 4.0. Mol Biol Evol 24:1596-1599 ten Hove RJ, van Lieshout L, Beadsworth MB, Perez MA, Spee K, Claas EC, Verweij JJ (2009) Characterization of genotypes of Enterocytozoon bieneusi in immunosuppressed and immunocompetent patient groups. J Euk Microbiol 56:388-393

Tumwine JK, Kekitiinwa A, Nabukeera N, Akiyoshi DE, Buckholt MA, Tzipori S (2002) Enterocytozoon bieneusi among children with diarrhea attending Mulago Hospital in Uganda. Am J Trop Med Hyg 67:299-303

USDA (2008) Beef 2007-2008, Part 1: reference of beef cow-calf management practices in the United States. USDA-APHIS-VS, CEAH, Fort Collins

van Gool T, Luderhoff E, Nathoo KJ, Kiire CF, Dankert J, Mason PR (1995) High prevalence of Enterocytozoon bieneusi infections among HIV-positive individuals with persistent diarrhoea in Harare, Zimbabwe. Trans R Soc Trop Med Hyg 89:478-480

Zhang X, Wang Z, Su Y, Liang X, Sun X, Peng S, Lu H, Jiang N, Yin J, Xiang M, Chen Q (2011) Identification and genotyping of Enterocytozoon bieneusi in China. J Clin Microbiol 49:2006-2008 